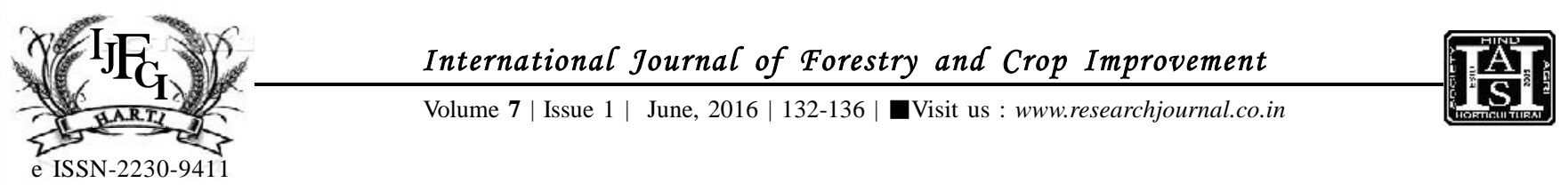

A CASE Study

DOI: $10.15740 / \mathrm{HAS} / \mathrm{IJFCI} / 7.1 / 132-136$

\title{
Forecast of banana - An economic analysis
}

\author{
M. UMA GOWRI AND B. KAVITHA
}

\begin{abstract}
The banana is an edible fruit, botanically a berry, produced by several kinds of large her baceous flowering plants in the genus Musa. Banana is a globally important fruit crop with 97.5 million tones of production. In India it supports livelihood of millions of people with total annual production of 16.91 million tones from 490.70 thousand ha. with national average of $33.5 \mathrm{~T} /$ ha. Banana contributes 37 per cent to total fruit production in India. Forecasting tools was used study of banana in Tamil Nadu. According to the MAPE value ARIMA method is most appropriate method for forecasting in banana. The cost and returns analysis reveals that higher net returns was realized in Nendran variety.
\end{abstract}

KEY WORDS : Banana, Forecating tools, Exponential smoothing, ARIMA model

How TO CITE THIS ARTICLE : Gowri, M. Uma and Kavitha, B. (2016). Forecast of banana - An economic analysis. Internat. J. Forestry \& Crop Improv., 7 (1) : 132-136, DOI: 10.15740/HAS/IJFCI/7.1/132-136.

Article Chronical : Received : 24.03.2016; Accepted : 30.05.2016 INDIA

Address of the Coopted Authors : B. KAVITHA, Department of Agricultural Economics, P.G.P. College of Agricultural Sciences, NAMAKKAL (T.N.) INDIA 